ORIGINAL ARTICLE

\title{
Efficacy of oral versus vaginal misoprostol in the management of first trimester incomplete miscarriage.
}

\author{
Afrah Aman', Laiyla Shinwari², Rehana Rahim ${ }^{3}$, Mehwish Syed $^{4}$, Rabia Nawaz $^{5}$
}

Article Citation: Aman A, Shinwari L, Rahim R, Syed M, Nawaz R. Efficacy of oral versus vaginal misoprostol in the management of first trimester incomplete miscarriage. Professional Med J 2022; 29(3):372-376. https://doi.org/10.29309/TPMJ/2022.29.03.6513

\begin{abstract}
Objective: To compare the efficacy of oral versus vaginal misoprostol in first trimester incomplete miscarriage. Study Design: Cross-sectional study. Setting: Gynae B Unit of Lady Reading Hospital, Peshawar. Period: November 2017 to January 2018. Material \& Methods: In this study 274 patients (i.e. 137 in each group) with incomplete miscarriage, who have gestational age of less than or equal to 12 weeks were included by convenience sampling. Women in group A had received 800 microgram oral misoprostol and women in group B had received 800 microgram vaginal misoprostol. In both groups same dose was repeated 4 hours after initial dose if the patient had not passed the product of conception. Patient who had no products of conception on pelvic ultrasound or Transvaginal scan were discharged from hospital. On the other hand patients found to still have products of conception were managed by surgical evacuation on next day. Results: In Group A (oral misoprostol) was effective in $n=115(84 \%)$ patients and ineffective in $n=22(16 \%)$ patients and Group $B$ (vaginal misoprostol) was effective in $n=125(91 \%)$ patients and ineffective in $n=12(9 \%)$ patients. No significant difference was found between the efficacies of the two routes. Age distribution among two groups was analyzed as in Group A mean age was $23.9 \pm 3.7$ years while in Group B it was $23.7 \pm 3.9$ years. Mean gestational age in group A was $68.8 \pm 1.6$ days and in group B was $68.7 \pm 1.3$ days. Insignificant difference was found when the age and gestational age of the patients of group $A$ and $B$ were compared. Conclusion: Vaginal misoprostol is equally effective as oral misoprostol in terms of expulsion of products of conception in patients with incomplete miscarriage.
\end{abstract}

Key words: $\quad$ First Trimester, Gestational Age, Misoprostol, Pregnancy.

\section{INTRODUCTION}

The Worlds Health Organization defines miscarriage as expulsion of fetus or embryo weighing $500 \mathrm{gm}$ or less and also gestational limit of less than 22 completed weeks of gestation. ${ }^{1}$ An incomplete miscarriage involves vaginal bleeding, cramping, dilatation of cervix and incomplete passage of the products of conception. ${ }^{2}$ Classically, the fetus has been passed, but some pieces of the placenta still remain in the uterus. The cervical oss remains open, and bleeding may be heavy. Incomplete miscarriage can be due to chromosomal abnormalities, hormonal problems, structural problems (shape of uterus), cervical issues, environmental factors, immunological causes, medications used for causing abortion and infections like German measles, cytomegalovirus, chlamydia and herpes simplex. ${ }^{3,4}$

Early miscarriage occurs in $10-30 \%$ of all pregnancies while $10-15 \%$ of all clinically recognized pregnancies.5,6,7 Almost 50-70\% of miscarriages are due to chromosomal abnormalities. Mostly miscarriages need proper and immediate treatment. Incomplete miscarriage is one of them which if not treated appropriately may result in various complications like psychological distress, prolong bleeding, longer cramping, increased risk of infection which can be dangerous if not treated immediately. ${ }^{8}$

Treatment options for incomplete miscarriage include expectant management, medical management and surgical management. Expectant management has low success rate.
1. MBBS, FCPS, Medical Officer Obstetrics \& Gynaecology, Qazi Hussain Ahmad Medical Complex, Nowshehra. 2. MBBS, FCPS, Medical Officer Obstetrics \& Gynaecology, Govt. Maternity Hospital Peshawar.

3. MBBS, FCPS, MRCOG, FRCOG, Professor Obstetrics \& Gynaecology, Lady Reading Hospital, Peshawar.

4. MBBS, FCPS, Medical Officer Obstetrics \& Gynaecology, Qazi Hussain Ahmad Medical Complex, Nowshehra.

5. MBBS, FPCS, Medical Officer, Tehsil Head Quarter Hospital, Dargai.

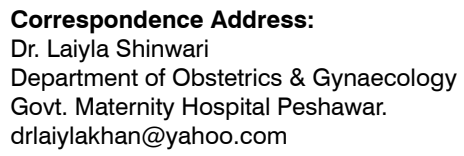

Correspondence Address:

Dr. Laiyla Shinwari

Department of Obstetrics \& Gynaecology

Govt. Maternity Hospital Peshawar.

drlaiylakhan@yahoo.com

Article received on:

Accepted for publication:

$11 / 06 / 2021$ 
Surgical management has high success rate but associated with major and minor morbidity like haemorrhage, infection, uterine adhesions and uterine perforation. ${ }^{9}$ Medical management with misoprostol is a reasonable alternative to universal surgical evacuation of the uterus in incomplete miscarriage. It is safe, inexpensive and effective method of treating incomplete miscarriage. ${ }^{10}$

Misoprostol is a synthetic prostaglandin $E_{1}$ analogue used in a number of clinical uses in the practice of obstetrics and gynaecology, including medical management of miscarriage, cervical ripening before surgical procedure, induction of labour and the treatment of postpartum haemorrhage. World Health Organization has kept misoprostol on the list of essential medicines because of its extensive applications in reproductive health. ${ }^{11}$ Moreover, it is cheaper and can be stored at room temperature. It can be given orally, vaginally and rectally but oral and vaginal routes are more common. ${ }^{8}$

Efficacy of misoprostol therapy can be influenced by route of drug administration. Both oral and vaginal routes are considered as noninvasive. Patients usually prefer oral route as its natural and culturally acceptable. On the other hand vaginal route by passes the first pass effect and is associated with less systemic adverse effects which oral route possesses. ${ }^{12}$ However, very less studies are done to compare the effectiveness of oral and vaginal misoprostol in managing incomplete abortion. If results of the present study show more or equal efficacy of vaginal route as compare to oral route, it will provide a good insight to the existing protocols for the management of incomplete miscarriage by avoiding systemic side effects and providing good efficacy.

\section{MATERIAL \& METHODS}

This cross-sectional study was performed in Obstetrics and Gynaecology unit ' $\mathrm{B}$ ' of Postgraduate Medical Institute (PGMI) Lady Reading Hospital, Peshawar after ethical approval. Duration of study was 3 months; November 2017 to January 2018. Total sample size calculated was 274 i.e. 137 in each group, using $91.9 \%$ efficacy of oral misoprostol and $79.6 \%$ efficacy of vaginal misoprostol ${ }^{13}, 80 \%$ power of test and $5 \%$ level of significance. ${ }^{14}$ Patients with incomplete miscarriage (confirmed by $\mathrm{U} / \mathrm{S}$ ), who have gestational age of less than or equal to 12 weeks were included in the study by convenience sampling. Patients with contraindication to misoprostol, uterus size more than 12 weeks, scar in uterus i.e. caesarean section or myomectomy scar, signs of severe infection like foul smelling discharge, fever $>39^{\circ} \mathrm{C}$, pulse $>110 /$ min were excluded from the study.

History was taken in detail from each subject. Period of gestation was calculated by dates. Per vaginal examination of patients were done to determine uterine size and pelvic/transvaginal scan (TVS) was done for the presence or absence of retained products of conception. After the diagnosis of incomplete miscarriage was done, study was explained to the patients and written informed consent was taken by maintaining their confidentiality. ${ }^{15,16,17}$ Women in group A had received 800 microgram oral misoprostol and women in group B had received 800 microgram vaginal misoprostol. In both groups same dose was repeated 4 hours after initial dose if the patient has not passed the product of conception, by repeating pelvic/TVS. Patients who have no products of conception on ultrasound (pelvic/ TVS) were discharged from the hospital. On the other hand patients found to still have products of conception on TVS were managed by surgical evacuation on next day.

\section{Data Analysis}

Data was analysed by using SPSS16 version quantitative variable like age and gestationage was described as mean and standard deviation (SD). Categorical variable like efficacy was described in terms of frequencies and percentages. Efficacy of the drugs administered through different routes between the two study groups was compared by Chi-square test. Efficacy was stratified among age and gestational age to see the effect of modifiers post stratification chi-square was also applied. P-value less than or equal to 0.05 was considered significant. 


\section{RESULTS}

Total patients were 274; they were divided in to two groups of 137 each. Women in group $A$ received 800 microgram misoprostol orally and women in group B received 800 microgram misoprostol vaginally. Regarding efficacy, oral misoprostol (Group A) was effective in 115(84\%) patients while vaginal misoprostol (Group B) was effective in 125(91\%) patients. An insignificant difference of $p$-value 0.06 was found when the efficacy of the two groups were compared.

In Group A mean age was $23.9 \pm 3.7$ years while in Group B it was $23.7 \pm 3.9$ years. Further subdivisions and details regarding age are shown in Table-I. Mean gestational age in group A was $68.8 \pm 1.6$ days and in group $B$ was $68.7 \pm 1.3$ days (Table-II). No significant difference was found between the age and gestational age of the two groups. Stratification of efficacy with respect to age and gestational age is given in Table-III and

\begin{tabular}{|l|c|c|}
\hline Age in Years & $\begin{array}{c}\text { Group A } \\
\text { (Oral } \\
\text { Misoprostol) } \\
(\mathbf{n = 1 3 7 )}\end{array}$ & $\begin{array}{c}\text { Group B } \\
\text { (Vaginal } \\
\text { Misoprostol) } \\
(\mathbf{n = 1 3 7 )}\end{array}$ \\
\hline $16-25$ & $14(10 \%)$ & $16(12 \%)$ \\
\hline $26-35$ & $41(30 \%)$ & $44(32 \%)$ \\
\hline $36-45$ & $82(60 \%)$ & $77(56 \%)$ \\
\hline Total & 137 & 137 \\
\hline Mean+SD & $23.9 \pm 3.7$ years & $23.7 \pm 3.9$ years \\
\hline
\end{tabular}

Table-I. Age of the patients. $(n=274)$

\begin{tabular}{|l|c|c|}
\hline $\begin{array}{c}\text { Gestation } \\
\text { Age in } \\
\text { Weeks }\end{array}$ & $\begin{array}{c}\text { Group A } \\
\text { (Oral Misoprostol) } \\
(\mathbf{n = 1 3 7 )}\end{array}$ & $\begin{array}{c}\text { Group B } \\
\text { (Vaginal } \\
\text { Misoprostol) } \\
(\mathbf{n = 1 3 7 )}\end{array}$ \\
\hline$<6$ & $21(15 \%)$ & $16(12 \%)$ \\
\hline $7-12$ & $116(85 \%)$ & $121(88 \%)$ \\
\hline Total & 137 & 137 \\
\hline Mean+SD & $68.8 \pm 1.6$ days & $68.7 \pm 1.3$ days \\
\hline
\end{tabular}

Table-II. Gestation age of the patients. $(n=274)$ IV respectively.

\begin{tabular}{|c|c|c|c|c|}
\hline Age in Years & Efficacy & $\begin{array}{c}\text { Group A } \\
\text { (Oral Misoprostol) } \\
(n=137)\end{array}$ & $\begin{array}{c}\text { Group B } \\
\text { (Vaginal Misoprostol) } \\
(n=137)\end{array}$ & P-Value \\
\hline \multirow{2}{*}{$16-25$} & Effective & 12 & 15 & \multirow{3}{*}{0.46} \\
\hline & Non-effective & 2 & 1 & \\
\hline Total & & 14 & 16 & \\
\hline \multirow{2}{*}{$26-35$} & Effective & 34 & 40 & \multirow{3}{*}{0.27} \\
\hline & Non-effective & 7 & 4 & \\
\hline Total & & 41 & 44 & \\
\hline \multirow{2}{*}{$36-45$} & Effective & 69 & 70 & \multirow{3}{*}{0.19} \\
\hline & Non-effective & 13 & 7 & \\
\hline Total & & 82 & 77 & \\
\hline
\end{tabular}

Table-III. Effect of age on efficacy of oral and vaginal misoprostol. $(n=274)$

\begin{tabular}{|c|c|c|c|c|}
\hline $\begin{array}{l}\text { Gestational Age } \\
\text { (Weeks) }\end{array}$ & Efficacy & $\begin{array}{c}\text { Group A } \\
\text { (Oral Misoprostol) } \\
(n=137)\end{array}$ & $\begin{array}{c}\text { Group B } \\
\text { (Vaginal Misoprostol) } \\
(n=137)\end{array}$ & P-Value \\
\hline$<6$ & Effective & 18 & 15 & \multirow{3}{*}{0.43} \\
\hline & Non-effective & 3 & 1 & \\
\hline Total & & 21 & 16 & \\
\hline \multirow[t]{2}{*}{$7-12$} & Effective & 97 & 110 & \multirow{3}{*}{0.09} \\
\hline & Non-effective & 19 & 11 & \\
\hline Total & & 116 & 121 & \\
\hline
\end{tabular}




\section{DISCUSSION}

Our study in Pakistan was performed to compare the efficacy of oral and vaginal misoprostol in the treatment of first trimester incomplete miscarriage. The results of this study showed that misoprostol was found almost equally effective in both group A (oral misoprostol) and group B (vaginal misoprostol). An insignificant difference of $\mathrm{p}-0.06$ was found between the efficacies of the two groups. No significant effect of age and gestational age was found on the efficacy of oral and vaginal misoprostol.

Pang et al., performed a randomized control trial (prospective) to compare the efficacy of oral and vaginal misoprostol $(800 \mu \mathrm{g})$ to manage incomplete miscarriage medically. Results confirmed the proper evacuation of uterus in $64.4 \%$ of cases who received oral misoprostol and $61.1 \%$ in cases treated with vaginal misoprostol. No significant difference was found between the efficacies of the two routes. ${ }^{10} \mathrm{Ngai}$ et al. also found the same results. ${ }^{18}$ The results of these studies are in accordance with the result of our study, as we also found no significant difference between the efficacies of the two routes.

A study was performed by Shokry and his colleagues in a hospital which was funded by Middle East Fertility Society. They gave the misoprostol vaginally to the patients attending their hospital who were diagnosed with incomplete miscarriage. Misoprostol by vaginal route was found to effectively evacuate the uterus from the products of conception in $79.6 \%$ of cases (Shokry). ${ }^{13}$ Kayastha et al also conducted a study in the obstetrics and gynaecology department of a tertiary care hospital of Nepal, they treated the patients of incomplete miscarriage with oral misoprostol which showed beneficial effects by properly evacuating the uterus in $91.9 \%$ of cases. ${ }^{14}$ The results of these studies are similar with our study as $91.2 \%$ was the effectiveness of the vaginal misoprostol.

Another study was performed in three major hospital of Vietnam, the patients presenting with incomplete miscarriage were included in the study to find the effectiveness of oral misoprostol in complete uterine evacuation from products of conception. Three hundred and two patients were enrolled in the study. Majority of the participants (96.3\%) successfully passed the products of conception after taking oral misoprostol. Uterine evacuation was later on confirmed by study clinicians in every single participant. ${ }^{19}$ We also found good efficacy (81.7\%) of oral misoprostol in uterine evacuation in first trimester.

Though vaginal route has many advantages but still certain studies have reported that many women prefer oral route as it is natural, convenient and culturally acceptable. ${ }^{20}$ Curettage needed in our study for uterine evacuation where misoprostol failed was less in vaginal route as compare to oral route.

In conclusion, both oral and vaginal misoprostol are equally effective in medical evacuation of incomplete miscarriage in the first trimester. Various studies have shown that vaginal route avoids first pass effect and is associated with minimum adverse effects. ${ }^{10}$ Therefore, we suggest that the vaginal route for misoprostol administration should be preferred.

\section{CONCLUSION}

Our study concludes that oral and vaginal misoprostol are equally effective in terms of expulsion of products of conception at uterine size of $<12$ weeks.

\section{Copyright $\subset 11$ June, 2021.}

\section{REFERENCES}

1. Chaudhry K, Nichols CJ, Siccardi MA. Blighted Ovum (Anembryonic Pregnancy). Available on URL: https:// www.ncbi.nlm.nih.gov/books/NBK499938/ [Accessed on 19-5-2020].

2. Pawde AA, Ambadkar A, Chauhan AR. A study of incomplete abortion following Medical Method of Abortion (MMA). J Obstet Gynaecol India. 2016 Aug; 66(4):239-43. DOI: 10.1007/s13224-015-0673-1.

3. Gebretsadik A. Factors associated with management outcome of incomplete abortion in Yirgalem General Hospital, Sidama Zone, Southern Ethiopia. Obstet Gynecollnt. 2018;3958681. DOI: 10.1155/2018/3958681. 
4. Mrunal. Incomplete miscarriage-causes, symptoms and treatment. Available on URL: https://parenting. firstcry.com/articles/incomplete-miscarriage-causessymptoms-and-treatment/ [Accessed on 19-5-2020].

5. Kim C, Barnard S, Neilson JP, Hickey M, Vazquez $\mathrm{JC}$, Dou L. Medical treatments for incomplete miscarriage. Cochrane Database Sys Rev. 2017: 5-15. DOI: $10.1002 / 14651858 . C D 007223$.

6. Shah $\mathrm{N}$, Syed SI, Khan NH. Sublingual versus vaginal misoprostol in the management of missed miscarriage. J Pak Med Assoc. 2010; 60(2):113-16.

7. Campillo ISL, Meaney S, Donoghue K, Corcoran P. Miscarriage hospitalizations: A national populationbased study of incidence and outcomes, 2005-2016. Reprod Health. 2019; 16: 51. DOI: 10.1186/s12978-0190720-y.

8. Stadler CN. Spontaneous miscarriage. In: Edmonds $\mathrm{K}$, Editor. Dewhurst text book of obstetrics and gynaecology. Eight Edition. London UK; WillweyBlackwell; 2012,p.54-57.

9. Sonsanosh A, Chullapram T. Comparison of sublingual and vaginal misoprostol for termination of early pregnancy failure: a randomized control trial. Thia $\mathrm{J}$ Obstet Gynaecol. 2014; 22:128-36.

10. Pang MW, Lee TS, Chung TKH. Incomplete miscarriage: A randomized controlled trial comparing oral with vaginal misoprostol for medical evacuation. Human Reprod. 2001; 16(11):2283-87. DOI: 10.1093/ humrep/16.11.2283.

11. Allen R, Brien BM. Uses of misoprostol in obstetrics and gynaecology. Rev Obstet Gynecol. 2009; 2(3): 159-168. DOI: 10.3909/riog0055.

12. Lete I, Dueñas JL, Esplugues JV, Marti-Cabrera M. Is the vagina an adequate route for the administration of hormonal contraceptives? Curr Drug Metab. 2010; 11(10):839-49. DOI: 10.2174/138920010794479646.
13. Shokry $M$, Fathalla $M$, Hussein $M$, Eissa $A A$. Vaginal misoprostol versus vaginal surgical evacuation of first trimester incomplete abortion: Comparative study. Middle East Fertility Society Soc J. 2013; 19:96101. DOI: 10.1016/j.mefs.2013.05.007.

14. Kayastah S, Tulashar H, Gurug S, Jaishe S. Use of oral misoprostol for treatment of incomplete abortion. Nepal J Obster Gynaecol. 2013; 8(2):30-33. DOI: 10.3126/njog.v8i2.9766.

15. Faisal R, Shinwari L. Comparative assessment of student's academic performance in multiple choice questions versus short essay questions in pharmacology examinations of a medical college of Pakistan. J Rehman Med Inst. 2015; 1:23-26.

16. Faisal R, Popalzai AJ, Sultana U. Class attendance of pharmacology students of Rehman Medical College as a determinant of academic performance. $J$ Rehman Med Inst. 2017; 3-4:14-20.

17. Shinwari L, Anwar A, Faisal R, Sibtain SA. Knowledge, attitudes and practices of health professionals towards antibiotic use in pregnancy: A crosssectional survey. Khyber Med Univ J. 2018; 10(1):2731.

18. Ngoc NTN, Shochet T, Blum J, Hai PT, Dung DL, Nhan TT et al. Results from a study using misoprostol for management of incomplete abortion in Vietnamese hospitals: Implications for task shifting. BMC Pregnancy Childbirth. 2013; 13; 118-22. DOI: 10.1186/1471-2393-13-118.

19. Ngai SW, Chan YM, Tang OS, Ho PC. The use of misoprostol for pre-operative cervical dilatation prior to vacuum aspiration: A randomized trial. Hum Reprod. 1999; 14(8):2139-42. DOI: 10.1093/ humrep/14.8.2139.

20. Parveen S, Khateeb ZA, Mufti SM, Shah MA, Tandon VR, Hakak $S$ et al. Comparison of sublingual, vaginal, and oral misoprostol in cervical ripening for first trimester abortion. Indian J Pharmacol. 2011; 43(2): 172-175. DOI: 10.4103/0253-7613.77356.

\begin{tabular}{|c||c|c|c|}
\hline \multicolumn{2}{|c|}{ AUTHORSHIP AND CONTRIBUTION DECLARATION } \\
\hline No. & Author(s) Full Name & \multicolumn{1}{|c|}{ Contribution to the paper } & Author(s) Signature \\
\hline 1 & Afrah Aman & $\begin{array}{l}\text { Conception \& design acquisition of } \\
\text { data, analysis \& interpretation of data, } \\
\text { Drafting the article \& revising it critically } \\
\text { for important intellectual content and } \\
\text { final approval of version. }\end{array}$ \\
\hline 2 & Laiyla Shinwari & $\begin{array}{l}\text { Design of the study, drafting the article } \\
\text { \& revising it critically for important } \\
\text { intellectual content, and final approval } \\
\text { of version. }\end{array}$ \\
\hline 4 & Rehana Rahim & Mehwish Syed & \\
\hline 5 & Rabia Nawaz & \\
\hline
\end{tabular}

